\title{
De la pintura española a un semanario argentino. Las portadas de Eugenio Fornells para Con Permiso
}

\section{From Spanish painting to an Argentine weekly magazine. Eugenio Fornells' Covers for Con Permiso}

\author{
Lorena Mouguelar \\ Universidad Nacional de Rosario. Argentina. \\ Imouguelar@gmail.com
}

\section{Resumen}

El artículo propone un análisis iconográfico de las portadas que Eugenio Fornells realizó para Con Permiso, semanario crítico editado en la ciudad de Rosario, Argentina, entre febrero y abril de 1919. Pese a la breve existencia de esta publicación, su estudio permite poner a foco los vínculos entre las tradiciones de la pintura occidental y ciertas ilustraciones impresas en Argentina a principios del siglo XX, así como la incidencia de las migraciones trasnacionales de creadores visuales en el tránsito de tendencias estéticas de un continente a otro. Las imágenes del artista catalán muestran un cruce productivo entre elementos de la alta cultura moderna y la prensa satírica masiva.

Palabras clave: revistas, iconografía, modernismo, migraciones, sátira.

\begin{abstract}
This article proposes an iconographic analysis of the covers made by Eugenio Fornells for Con Permiso, a critical weekly magazine published in the city of Rosario, Argentina, between February and April of 1919. Despite the short life of this publication, its study allows us to focus on the ties between the traditions of western painting and certain illustrations printed in Argentina in the early $20^{\text {th }}$ century, as well as on the impact that the transnational migrations of visual creators had on the trajectories of aesthetic trends from one continent to the other. The Catalan artist's images show a productive crossing between elements of high modern culture and the massive satirical press.
\end{abstract}

Keywords: Magazines, Iconography, Modernism, Migrations, Satire. 


\section{El humor y la inmigración española}

Entre los meses de febrero y abril de 1919, cada sábado y en forma ininterrumpida salió a la venta en Rosario el semanario crítico ¡Con Permiso!, una publicación “con grabados en el texto" que abordó problemáticas de actualidad nacional y regional desde el lenguaje humorístico. Mediante la representación satírica de referentes políticos y sociales de la época, sus directores se propusieron "como los poetas de otros

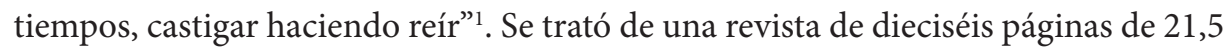
x $30 \mathrm{~cm}$., editada en papel rústico y con la portada a dos tintas, que -según los datos difundidos por el mismo equipo de redacción- alcanzó tiradas de 6.000 ejemplares. Su materialidad modesta y precio accesible, así como la profusión de imágenes que la ilustraron, la brevedad de los textos y la apelación constante al lenguaje coloquial, permite caracterizar al lector modelo a quien se dirigió. Un lector de clases medias o populares en ascenso, conocedor tanto de los modismos y costumbres de los diferentes grupos inmigratorios arribados a la Argentina, como de la actualidad socio política que la revista parodiaba. En efecto, $;$ Con Permiso! no se propuso informar, sino entretener y al mismo tiempo incentivar la construcción de un pensamiento crítico sobre la realidad cotidiana. Una nueva estrategia de interpelación por parte de la prensa desarrollada entre otras como respuesta ante la aparición de un nuevo público masivo que incorporó a sectores populares, tanto nativos como de origen inmigratorio (Saítta 448-51). A diferencia de otras revistas ilustradas de la época, no incluyó fotografías en sus páginas. En su lugar la publicación ofreció un gran despliegue de dibujos muy cuidados a nivel estético cuyo número fue variando en cada una de las ediciones. Las imágenes bascularon entre la caricatura política y la sátira social, buscando en todo momento provocar la risa y la complicidad del lector.

Tras alcanzar los trece números, ;Con Permiso! dejó de editarse por razones financieras. Este hecho fue frecuente en los inicios de una nueva prensa comercial y, en cierto sentido, moderna que había dejado atrás los rasgos del periodismo faccioso del siglo XIX y ensayaba diversas estrategias para adecuarse a las exigencias del mercado (Mauro, Cesaretti y Uliana 122). Pese a la breve existencia de esta publicación, su estudio resulta significativo en la medida en que permite poner a foco los vínculos entre las tradiciones de la pintura europea y ciertas ilustraciones impresas en Argentina a principios del siglo XX, entre saberes académicos y productos de la industria cultural, entre alta cultura y cultura de masas, dos ámbitos escindidos por el pensamiento moderno que en las últimas décadas han sido objeto de múltiples revisiones (Huyssen 35-7). En el marco de los diversos análisis sobre las relaciones productivas entre arte y el amplio campo comprendido por la cultura

1 Hoja publicitaria de ¡Con Permiso! firmada por "Los padres de la criatura", que fue distribuida a finales de enero de 1919 junto a un afiche con caricaturas de políticos y personalidades de la cultura santafesina. Ambas piezas gráficas fueron impresas también con el formato y papel de la revista e incluidas en el primer número, sin paginar. 
visual (Marchán Fiz 75-90), nos proponemos rastrear la apelación a estéticas y modelos iconográficos de la pintura europea en el diseño de imágenes para una revista editada en nuestro país.

La presencia a comienzos del siglo XX en las redacciones de diarios y revistas de pintores formados en las disciplinas canónicas de las bellas artes fue resultado tanto del proceso de profesionalización de los artistas plásticos, como de un estado incipiente en la constitución del campo artístico que tornaba indispensable el desarrollo de tareas vinculadas a las artes aplicadas en tanto medio de sostenimiento económico (Szir, "Entre el arte y la cultura masiva" 128). A su vez, las migraciones transnacionales de creadores visuales así como la recepción de una profusa cantidad de publicaciones ilustradas provenientes de Europa favorecieron el tránsito de tendencias estéticas de un continente a otro y en consecuencia, la disponibilidad de un amplio vocabulario formal que fue seleccionado y apropiado en clave local por los artistas latinoamericanos o extranjeros radicados en nuestras tierras.

¡Con Permiso! fue dirigido en forma conjunta por el periodista y escritor Pedro Julio Cabañero y los dibujantes Eugenio Fornells y José Andrade. Éste último era descendiente de andaluces y los dos primeros, inmigrantes provenientes de Cataluña que hacia 1919 llevaban más de una década viviendo y trabajando en Rosario. Con esta propuesta retomaban una tradición de humor gráfico y escrito en el periodismo argentino que en gran medida habían contribuido a forjar sus compatriotas desde finales del siglo anterior. En efecto, los artistas españoles, residentes por un cierto lapso de tiempo o radicados definitivamente en nuestro país, habían incidido de manera determinante en la posibilidad de pensar el "humor como un fuerte elemento de crítica política" (Neveleff y Di Iorio 5). Un caso paradigmático dentro del periodismo satírico decimonónico fue el periódico Don Quijote, fundado en Buenos Aires en 1884 y dirigido por el madrileño Eduardo Sojo, con las colaboraciones gráficas de José María Cao y Manuel Mayol (Malosetti Costa, "Los "gallegos", el arte y el poder de la risa” 255). Estos inmigrantes que por razones legales no podían participar directamente en la vida política argentina, hallaron en las artes gráficas un arma más o menos sutil de intervención y una vía de expresión pública de sus ideas e ideales que en ocasiones debió soportar los límites de la censura. Pocos años más tarde, el surgimiento del semanario popular ilustrado fusionó la revista artístico-literaria con elementos de la prensa satírica, apelando a un público masivo reclutado entre las nuevas capas medias de la sociedad urbana (Szir, Infancia y cultura visual 25). Luego de una experiencia en Montevideo, en 1989 Eustaquio Pellicier introdujo este nuevo formato periodístico en Buenos Aires con la segunda época de Caras y Caretas. De la dirección artística se hizo cargo en principio otro español, el mencionado Manuel Mayol. Dentro del devenir de la prensa en Rosario, diversos proyectos editoriales precedieron y posibilitaron la emergencia de ¡Con Permiso!: tanto los periódicos satíricos decimonónicos locales como las revistas ilustradas que circularon desde comienzos del siglo XX y que incluyeron humor gráfico en sus páginas (Söhle 158- 
$160)^{2}$. Entre estas últimas figuraron Monos y Monadas (1910-1913), Gestos y Muecas (1913-1914), ABC (1915), Don Pánfilo (1917), publicaciones periódicas con las que en mayor o menor medida estuvo vinculado Eugenio Fornells.

Desde su cargo de director artístico de ¡Con Permiso!, Fornells realizó los cabezales y gran parte de las portadas y gráficas interiores de la revista. Sus diseños constituyeron un conjunto de trabajos cuya calidad y complejidad se sostuvo en la destreza en el oficio que su autor había obtenido con los años, en el profundo conocimiento de la historia del arte y en su familiaridad con el humor gráfico tanto en España como en Argentina. Para poder desplegar estas cuestiones, en esta ocasión analizaremos en detalle la iconografía de cada una de las portadas que Fornells firmó como "Pim", seudónimo elegido para esta publicación.

\section{El bagaje de conocimientos y experiencias}

Al momento de planear el lanzamiento de ¡Con Permiso!, Eugenio Fornells (18821961) contaba con una importante trayectoria en el campo de las artes visuales en general y de la ilustración satírica en particular. Luego de terminar sus estudios en la Academia Fortuny de Reus, su ciudad natal, se había desplazado hacia Barcelona. Allí completó su formación en la Academia Baixas, al tiempo que participaba en las reuniones del Círculo Artístico de Sant Lluc donde recibió las enseñanzas de Josep Llimona. Por este ámbito pasaron muchos pintores y escultores destacados dentro del modernismo catalán, tales como Joan Llimona, Miguel Blay y Alexandre de Riquier (Bozal 32). También en Barcelona ejerció la docencia y trabajó hacia 1907 como ilustrador en diversas publicaciones periódicas de tendencia republicana ligadas al lerrouxismo (Culla y Clarà 58), tales como La Rebeldía, ¡Are més que mai! o La Kábila, evidenciando definidas inclinaciones políticas que mantendría a lo largo de toda su vida.

En 1908 Fornells emigró con destino a la Argentina y desarrolló, en forma paralela a su obra pictórica, una serie de tareas ligadas a la enseñanza y a las artes aplicadas que le permitieron obtener el sustento diario (Boni 42). En Buenos Aires se unió como colaborador gráfico al equipo del periódico vespertino Última Hora, fundado en mayo de ese mismo año. En tanto exponente de las nuevas formas del periodismo masivo y popular, esta publicación ofreció a sus lectores una gran cantidad de ilustraciones que favorecieron el acceso al material escrito de un modo más relajado y dinámico (Saítta 448). Posteriormente, ya establecido en la ciudad de Rosario, actuó como ilustrador de diversas revistas a lo largo de la década del diez. Entre ellas, Caras

2 Entre los periódicos satíricos publicados desde mediados del siglo XIX, cabe destacar La Bomba dirigida por Alberto Linares en 1894 y donde colaboró Cao con sus caricaturas. 
y Caretas (1898-1939) de Buenos Aires y semanarios locales como Gestos y Muecas (1913-1914) y El Teatro (1912), del que también fue director artístico.

Fornells mantuvo por largos años fuertes conexiones con su patria de origen y con otros inmigrantes catalanes, con quienes se asoció en diversos proyectos comerciales, culturales y educativos. En 1914 fundó en Rosario la Agrupación Artística Catalana, que más tarde se uniría al Centre Catalá, y a partir de entones también organizó durante tres años en el Salón Souza exposiciones colectivas de pinturas de artistas catalanes. Regularmente recibía periódicos y revistas españoles que lo mantenían informado sobre la actualidad política y cultural. Entre ellos podemos mencionar La Ilustración Artística, editada en Barcelona y profusamente ilustrada con dibujos y reproducciones de obras. Asimismo, era un ávido lector de semanarios porteños como la mencionada Caras y Caretas o PBT, donde habitualmente aparecían notas referidas a la península ibérica y gran cantidad de dibujos y caricaturas de otros inmigrantes españoles residentes en Buenos Aires. Inclusive, durante casi todo el año 1917 pasó una larga estadía en su ciudad natal a donde regresó con varios objetivos: en primer término, reencontrarse con su familia, pero también actuar como comisionado del Ateneo Popular de Rosario para estudiar la organización y funcionamiento de asociaciones culturales españolas, y paralelamente, dedicarse al desarrollo de su obra paisajística.

Hacia 1919, año de edición de la revista que nos ocupa, Eugenio Fornells tenía una imagen gráfica definida y reconocible pese a los distintos seudónimos con los que muchas veces firmó las caricaturas. La línea segura y orgánica, con énfasis, modulaciones y un marcado carácter decorativo, evidenciaba sus vínculos con el modernismo catalán. Fornells cruzó estos elementos estéticos con procedimientos de la prensa satírica española y modelos iconográficos profundamente instalados en la cultura occidental. El resultado fue una serie de visiones sobre la vida política argentina, comprensibles entre un público amplio y de excelente factura. Para las portadas de ¡Con Permiso! conjugó imágenes y palabras de su propia autoría, en composiciones equilibradas aunque no exentas de dinamismo. Inclusive en aquellos pocos números cuya primera página estuvo a cargo de otro dibujante, su trabajo se hizo presente a través del diseño del cabezal.

\section{El bufón junto al título}

La tapa de la revista era el primer estímulo visual que recibía el lector y en cierta medida, a su eficacia comunicativa se debía el hecho de que éste decidiera comprarla o no. El cabezal era el único elemento fijo dentro de la diagramación de la portada, cuyo simbolismo informaba a simple vista sobre las características de la publicación. En el caso de ¡Con Permiso!, se trató de un personaje bufonesco, síntesis gráfica del sentido tragicómico de las lecturas sobre la realidad que ofrecía la revista. El semanario 
humorístico proponía así cumplir una función compensatoria: se presentaba como consuelo ante hechos dolorosos o preocupantes en la vida cotidiana del ciudadano medio de la región. En palabras de Peter Berger, la tragicomedia constituye un tipo de comicidad que "no erradica el dolor o la tristeza que pueda haber en ella, pero hace más soportable estas emociones" (197). De un modo similar, aunque preservando el tenor gracioso de sus aportes, José Andrade definía en la última nota editorial la labor desplegada a lo largo de trece entregas en las que ¡Con Permiso! le había estado "haciendo cosquillas al vecindario y endulzándole su existencia amargada constantemente por el gobierno, el casero, el sastre, el proveedor y el Banco Municipal de Préstamos" (CP 13, 3).

A excepción de la quinta tapa de la revista, las diez primeras llevaron impreso en el tercio superior del soporte un cabezal que, pese a no tener firma, por su similitud estilística con otros dibujos podemos atribuir a la mano de Eugenio Fornells. Se trataba de un hombre de aspecto humilde y rasgos bien marcados, de cejas anchas, ojos saltones, nariz y orejas prominentes, y una amplia sonrisa rodeada por la barba crecida de un par de días. Un personaje rústico, desaliñado y hasta feo, con cierta expresión de tristeza en su mirada, que por su aspecto físico podía provocar la risa burlona del público al igual que los bufones en épocas pasadas (Eco 140). El hombre estaba sentado sobre el suelo con sus piernas extendidas hacia delante, imitando la postura del famoso bufón Don Sebastián de Morra (c. 1645) de Diego Velázquez. Quizás Fornells intentaba así remitir a uno de los sentidos de esta obra: la denuncia sobre el modo en que "en la corte se convertía a estas personas en objeto de desvergonzado espectáculo, burla y demostración de poder” (Walther 270). El protagonista del cabezal de ¡Con Permiso! también era un hombre común, un trabajador igual que el posible lector -maltratado directa o indirectamente por el accionar de políticos o personas en mejor situación económica-, que el semanario venía a aliviar y, en cierta medida, a vindicar mediante la risa. Esta posición corporal hacía que las suelas de sus zapatos quedasen frontales al espectador, en primer plano, dejando a la vista unas líneas que insinuaban en esa superficie rugosa las máscaras simbólicas de la comedia y la tragedia. Finalmente, un manojo de cascabeles atados con una soga al traje subrayaba el carácter cómico y festivo de la revista, así como la interpretación del personaje desgreñado en tanto bufón, aquel súbdito que en las cortes hacía reír a los poderosos con sus palabras y acciones al tiempo que los enfrentaba a la realidad cotidiana del resto de la sociedad riéndose de ellos. La figura condensaba así también otra propuesta fundamental dentro del semanario: el uso de la sátira como arma, la intención manifiesta de bañar "en la tina del ridículo" a los políticos y a la humanidad farsante, de "castigar, haciendo reír"3.

El bufón sostenía un cartel con el título de la revista: ¡Con Permiso! se podía leer en grandes letras características del modernismo catalán. Una tipografía orgánica,

3 Hoja publicitaria de ¡Con Permiso!, cit. 
de líneas curvas y formas llenas, con los espacios intermedios delineados por un fino grafismo. Sin explicitar el motivo, los últimos tres números de la revista mostraron un cambio rotundo en esta presentación gráfica: se eliminó el dibujo del cabezal y se mantuvo sólo la leyenda, se optó por una tipografía de palo seco, geométrica y en negro pleno, obteniendo un máximo contraste con el fondo, quizás con el objetivo de otorgar mayor visibilidad a la caricatura de la semana.

\section{La sátira sobre la política provincial}

La mayoría de las portadas fueron impresas a una tinta, con el agregado de planos de un color variable que resaltaban ciertas zonas de los dibujos y las letras. Sin embargo, las tres que abordaron específicamente asuntos relativos a la política provincial quedaron sólo en blanco y negro. Las tapas funcionaron como editoriales gráficos, satirizando alguna noticia de actualidad e inclusive anticipándose a la nota editorial que bajo el título "Como íbamos diciendo..." escribía José Andrade cada semana y firmaba con el nombre de pluma "Pancho". Tal fue el caso de la portada del primer número de ;Con Permiso!, que de un modo similar al editorial publicado en la entrega siguiente, aludía a la puja que se daba en Santa Fe entre distintas facciones del Partido Radical en su lucha por posicionarse frente a los sectores gobernantes (Karush 57). En la imagen titulada "Política provincial" aparecían en un interior burgués "Manuela", "el cordobés" y "el gaucho" (CP 1, 1): el ex - gobernador de Santa Fe, con vestido largo y un gran medallón con el rostro del presidente de la Nación, escuchaba en su sala de visitas las propuestas de otros dos representantes del radicalismo. La fidelidad de los rostros caricaturizados con respecto al referente y el conocimiento por parte del lector de la época del aspecto físico de los distintos contendientes políticos, tornaba prescindible la aclaración de las identidades junto a los apodos. Fornells lograba captar y sintetizar la fisonomía de los retratados, con los que el lector presumiblemente estaba familiarizado merced al consumo paralelo de prensa "seria", al tiempo que generaba un efecto caricaturesco sin necesidad de exagerar sus rasgos físicos, salvo un ligero aumento en el tamaño de cabezas, pies y manos. La gracia de las imágenes estaba dada por el sentido burlesco con que se hacía referencia a sus actitudes o acciones. Los políticos aparecían travestidos, buscando pactos, comprando y vendiendo voluntades, haraganeando, peleando o compitiendo entre ellos de un modo ridículo, despojados de cualquier dignidad inherente al cargo que ocupaban.

La portada del número nueve otra vez parodiaba las luchas de poder entre los tres sectores del radicalismo en la provincia de Santa Fe, a través de la representación de dirigentes de gran visibilidad pública. En medio de un "Remate-feria" de ganado, cada uno ofrecía su rebaño de ovejas a Hipólito Yrigoyen, primer mandatario electo por el voto popular tras la aprobación de la denominada Ley Sáenz Peña (Persello 
61-2) ${ }^{4}$. En esta ocasión se consignaban sus nombres: Enrique Mosca, Néstor Noriega y Ricardo Caballero intentaban convencer al presidente de la Nación sobre las bondades de sus respectivos lotes de mansos electores. A ellos mismos hacía referencia Andrade desde su columna a la semana siguiente, en una frase dura e irónica: "un pueblo que olvida su propia situación, sugestionándose por contiendas de carácter personal o partidista, que nada pueden variar la marcha de los acontecimientos [...], ese pueblo ha perdido su derecho a queja. Tiene el gobierno que merece" (CP 10, 3) Este caso particular nos permite señalar que el semanario no fue concesivo en su crítica mordaz con ningún sector de la vida política, ni siquiera con el electorado. Del mismo modo que satirizaba a gobernantes y representantes de los sectores opositores, las actitudes indolentes de la ciudadanía ante la inacción y los abusos de los políticos o la falta de organización de la masa obrera urbana y rural fueron objeto de punzantes observaciones. Tanto desde el lenguaje visual como desde el escrito, se intentó propiciar una nueva lectura de la realidad favoreciendo el desarrollo de un pensamiento crítico por parte del pueblo.

Finalmente, en el número doce un miembro del partido gobernante volvió a protagonizar la caricatura de tapa. En esta ocasión se trataba de Calixto Rodríguez, quien era presentado como "Un cristo radical", una parodia que probablemente se haya originado en alguna queja o comentario del propio Calixto. Siguiendo la clásica iconografía de Cristo en la cruz y rodeado por versos satíricos sobre su desinteresada generosidad en tanto "mecenas político", se veía a Calixto cubierto sólo por el paño de la pureza y sostenido por cuatro grandes clavos (CP 12, 1). El Cristo crucificado (1638) de Diego Velázquez, uno de sus cuadros más populares según Camón Aznar (366), parecía ser el referente directo de la imagen. Tanto en esta pintura como en el dibujo de Fornells, a la disposición del cuerpo en contraposto y la suave curva generada por los brazos, a la cabeza levemente inclinada hacia abajo y los ojos cerrados, se sumaba el rotundo contraste entre la luz de la figura y la oscuridad total del fondo. La conmemoración de la Semana Santa sirvió de leitmotiv a los ilustradores de ¡Con Permiso!, quienes apelaron a distintas escenas alegóricas para organizar las caricaturas. En este sentido, la portada anunció el despliegue iconográfico de las páginas interiores.

\section{La política nacional desde la comicidad y la parodia}

Los comicios en Buenos Aires para cubrir un cargo en el Senado de la Nación, vacante tras la renuncia de quien fuera elegido gobernador, motivaron dos portadas. En el

4 En 1912, la reforma de la ley electoral incorporó la obligatoriedad y el secreto del voto para todos los ciudadanos argentinos varones. Su aplicación dio como resultado el triunfo del Partido Radical en distintos territorios provinciales, entre ellos Santa Fe, mientras que a nivel nacional, se sucedieron tres gobiernos de este mismo signo político entre 1916 y 1930. 
número siete, ubicados sobre un triángulo compositivo tres gallos se enfrentaban por un plato de comida. Los animales tenían los rostros de los candidatos de los partidos en puja: el demócrata progresista Lisandro de la Torre, el radical Vicente Gallo y el socialista Juan B. Justo. La representación zoo antropomorfa de los políticos como "gallos de riña" resultaba tanto del juego de palabras con el apellido de uno de los contendientes como de sus características combativas, destacadas a la semana siguiente en la nota editorial. Aunque el autor reconocía en el texto las "capacidades probadas" de los candidatos y sus posibilidades de "realizar obra patriótica, de bien público" (CP $8,3)$, la imagen restaba toda solemnidad al asunto y transmitía cierto escepticismo por parte del dibujante ante las próximas elecciones, generando un contrapunto con respecto al sentido propuesto por las palabras. El uso de la caricatura, como señala Peter Burke, constituyó:

una aportación fundamental al debate político, desterrando la mistificación del poder y fomentando la participación de la gente sencilla en los asuntos de estado. Estos dibujos consiguieron dichos objetos mediante la presentación de temas controvertidos de una forma simple, concreta y memorable, y mostrando a los principales actores del drama político como mortales falibles y en modo alguno heroicos (Visto y no visto 100).

El hecho de que el escrutinio se dilatase por más de un par de semanas hizo que recién en el número once la portada aludiera al resultado final. La victoria de Gallo por muy poca diferencia de votos provocó más de un comentario con respecto a su legitimidad. Esta vez, los candidatos competían en el juego del palo enjabonado por el queso enganchado en la punta. De nuevo el puesto en pugna era representado simbólicamente a través de un alimento, en clara referencia a las grandes erogaciones estatales justificadas en concepto de dietas. Las posiciones en el juego estaban en consonancia con los votos recibidos por cada uno y la evaluación de sus respectivas situaciones en el nuevo mapa político: Gallo en la cima pero inestable, De la Torre tumbado de espaldas en el piso y Justo sentado sobre este último, sugestivamente en una posición similar a la del bufón ausente en esta portada.

La apelación a este juego de agilidad física para caricaturizar a los candidatos principales en una justa política no era vista por primera vez en nuestra ciudad. Ya en 1913, Jacobo Abramoff había recurrido al mismo motivo para referirse a las elecciones de intendente en Rosario desde la portada interior del semanario Gestos y Muecas 9 (s/p). Sin embargo, el formato vertical utilizado por Fornells para plasmar la competencia y la aparición de un único palo remitía más directamente al óleo La cucaña (1787) de Francisco Goya, nombre del juego popular español que había pasado luego a la Argentina criolla. Los tres niños que en la pintura de Goya se trepaban y luchaban por alcanzar primero la cima con el premio, fueron reemplazados en la caricatura de Fornells por los candidatos de turno. Del artista también habría tomado la audacia de mofarse de las personalidades que representaba. Según Ernst Gombrich (401), en 
los retratos de la corte española se hacía visible la voluntad de Goya de poner al descubierto mediante sutiles detalles la vanidad y la fealdad de sus protectores. Muchos de sus trabajos contenían visos caricaturescos que sólo se desarrollarían en España un siglo más tarde.

Las referencias a la política nacional también emergieron en las parodias de otros medios periodísticos, ofreciendo una visión contrapuesta de los mismos hechos. En el tercer número, el epígrafe de la caricatura transcribía una frase del diario oficialista La Época de Buenos Aires: "El señor Presidente, que viene preocupándose, desde que asumió el poder, de la solución rápida, eficaz y patriótica de los grandes problemas nacionales.... En este caso, la imagen otorgaba un nuevo sentido al texto, cuestionando la veracidad de los relatos difundidos por el periódico porteño. La caricatura contigua mostraba dos planos contrapuestos en varios sentidos: un interior donde prevalecían las direcciones horizontales, con su sentido de reposo y quietud; un exterior configurado por verticales, donde predominaban la acción y el ruido. Dentro de la habitación, recostado en un sofá, estaba el presidente Hipólito Yrigoyen descansando con sus ojos cerrados, cigarrillos, un libro y papeles sueltos esparcidos por el piso. Más allá del gran ventanal una muchedumbre en huelga pedía por "pan y trabajo", mientras por un lateral entraba en escena la policía reprimiendo a los manifestantes.

La oposición y la estrecha conexión entre las situaciones que se desarrollaban simultáneamente en dos espacios diferentes recordaba en cierta medida al esquema compositivo de Sin pan y sin trabajo (1893) de Ernesto de la Cárcova, donde también a través de una ventana se divisaba el enfrentamiento entre obreros y la guardia montada. En 1908, año de llegada de Eugenio Fornells a Buenos Aires, la exitosa pintura fue reproducida en la revista Athinae (Malosetti Costa, "Ernesto de la Cárcova" 427) por lo que es casi seguro que el autor la conociese. Esta imagen clave dentro del arte moderno en Argentina, que por primera vez tematizó la cuestión social y las luchas de los trabajadores, fue objeto de sucesivas reapropiaciones mostrando su capacidad de reactivarse en momentos de crisis (Malosetti Costa, "Tradición, familia, desocupación” 3). Otra cita detectable en la caricatura de Fornells estaba dada a través de un personaje ubicado en el centro del primer ventanal, que era prácticamente igual al protagonista de El grito (1893) de Edvard Munch. A su vez, las líneas onduladas que contorneaban las ropas de los manifestantes conformaban planos vibrantes similares al tratamiento del paisaje en aquel mismo cuadro.

\section{Del carnaval a la despedida}

El grupo de redacción de ¡Con Permiso! fue caricaturizado en pleno para el número cinco. Siguiendo la lógica de las fiestas de carnaval y dejando por un tiempo el lugar de observadores críticos, los integrantes del semanario se convirtieron en objeto de sus propias bromas. Redactores e ilustradores se rieron de sí mismos utilizando las 
mismas estrategias visuales con las que habitualmente generaban una visión satírica de los políticos: vestidos de mujer, con aspecto de animales o disfrazados, pero siempre con una amplia sonrisa.

En este número hubo un cambio transitorio en el cabezal. Se eliminó el dibujo y la tipografía se regularizó, dejando más espacio para la caricatura central. Los cascabeles que adornaban el cartel pasaron a formar parte del traje de "payaso bochinchero" de Julio Cabañero, quien hacía sonar el bombo y los platillos. El rostro de José Andrade apareció en el cuerpo del "mono Pancho atorrante", ataviado con un pequeño sombrero y llevando una gran pluma en su mano. Eugenio Fornells se auto-caricaturizó como "bailarina incitante", de vestido corto y medias a rayas, arreglo floral y un bastón para la coreografía. Detrás de los directores, en pequeños afiches pegados en la pared estaban los retratos del resto de los colaboradores: "cabeza parlante" era el rostro del dibujante Julio Vanzo sobre una bandeja, su colega Jacobo Abramoff era caricaturizado con el epígrafe "aquí hay musculatura. Dr. Off”, "la niña gorda”, el "ilusionista”, "el menos negro" y el "pateador" eran los restantes componentes del equipo que no pudimos identificar.

A la semana siguiente la portada mostró las secuelas de los festejos del carnaval. Borrachos y sentados en el piso en medio de serpentinas, el pobre junto al rico eran, al menos por unas horas, iguales en este mundo: "El alcohol, partidario del maximalismo crudo, abolió la diferencia de clases, con el peludo (sic., borrachera en lunfardo)" (CP 6, 1). La simetría espejada en la composición reforzaba la idea de subversión de las jerarquías propia de las fiestas carnavalescas, que permitía equiparar a hombres pertenecientes a distintos estamentos sociales. El "ricacho" con galera casi dormido no notaba que se estaba derramando el champagne. A su lado, el "pobretón" con chambergo seguía tomando vino de la botella, ubicando sus manos como si se tratase de una típica bota española. Su postura recordaba en este sentido otro óleo de Francisco Goya, El bebedor (1777-1778) con sus dos majos descansando en una pradera, uno de ellos bebiendo a la manera catalana.

La última portada de ¡Con Permiso! también fue protagonizada por sus directores. Ellos mismos habían anunciado la clausura del proyecto editorial, asegurando que cerraban su balance con un cero, sin ganancias pero sin deudas (CP 12, 3). Pese a la buena recepción por parte del público local y al relativo apoyo de los auspiciantes, la falta de rédito económico fue el factor determinante en el cierre del semanario. La resistencia del grupo a plegarse a prácticas habituales en el campo periodístico de la época, como el favor de los partidos políticos o la apelación al chantaje, tornó imposible el sostenimiento financiero de la revista a lo largo del tiempo (Mouguelar $14)^{5}$. Luego de tres meses de intenso trabajo, llegó la despedida definitiva. Fornells, Cabañero y Andrade saltaban sonrientes, empuñando grandes plumas y estilográ-

5 La opción por una existencia autónoma de los poderes e intereses políticos en un momento de emergencia de una prensa moderna, así como la competencia con otras publicaciones periódicas que comenzaron a editarse en Rosario en forma simultánea, fueron factores hipotéticos de su corta existencia en el mercado. 
ficas como si se tratara de lanzas, provocando un estallido (CP 13, 1). En el instante en que todos estaban suspendidos en el aire, Fornells retomaba la postura de aquel bufón de las portadas iniciales con sus piernas extendidas hacia delante, generando una identificación entre director y medio gráfico, muy común en la prensa satírica ${ }^{6}$.

Del mismo modo que en la primera portada del carnaval, el grupo de ${ }_{i} C o n$ Permiso! se mostraba divertido, disfrutando de su tarea cotidiana, riéndose inclusive de sus penurias económicas:

¡Con Permiso! se retira risueñamente del foro [...] ha cosechado muchos laureles en los tres meses que lleva rodando por la ciudad, y como de laureles ha debido mantenerse, cree más conveniente y más nutritivo dedicarse a barrendero, peón de cocina, actor nacional o tonadillera. [...iCon Permiso! se habría] satisfecho con muy poca cosa, porque también la gozaba como un chancho, en el reparto de cosquillas, pellizcos, alfilerazos, sorpresas y solos de violín... Como no es lo mismo poca cosa, que nada, y el que nada no se ahoga, resuelve hacer un paréntesis a sus salidas, y quedarse en casa, donde por lo menos, descansará y no gastará el aserrín del cerebro y la suela de los botines, dos elementos que ha consumido sin habérsele facilitado los repuestos (CP 13,3).

En este sentido, el semanario reafirmaba la fuerte identificación con el lector popular al que iba dirigido. Todos eran trabajadores que soportaban los mismos males sociales y políticos, en muchos casos inmigrantes o hijos de inmigrantes que buscaban construir un espacio propio en una cambiante ciudad moderna. Frente a estos avatares, unos y otros contaban con un arma poderosa en la lucha contra las injusticias, que a su vez constituía un elemento compensatorio inalienable para las angustias cotidianas: la risa. Humor gráfico, citas visuales de la pintura occidental canónica, referencias estéticas al modernismo catalán y crítica socio-política se conjugaron en las imágenes de este proyecto periodístico orientado por un fuerte sentido utópico, cuya dificultad para adecuarse a los requerimientos comerciales de la nueva prensa rosarina determinó en gran medida su prematuro cierre.

\section{Referencias}

Berger, Peter. Risa redentora. La dimensión cómica de la experiencia humana. Barcelona: Kairós, 1999. Medio impreso.

Boni, Nicolás. "Imágenes modernistas en Rosario en los inicios del siglo XX: vitrales, mayólicas y pinturas murales". Separata 16 (2011). 33-47. Medio impreso.

6 Pensamos en particular en dos periódicos satíricos editados en Buenos Aires a finales del siglo XIX: en el personaje arlequinesco de El mosquito dirigido y dibujado en sus primeros tiempos por Henry Meyer o en la figura heroica de El Quijote, de Eduardo Sojo. 
Bozal, Valeriano. Summa Artis. Pintura y escultura españolas del siglo XX (1900-1939), Vol. XXXVI. Madrid: Espasa-Calpe, 1993. Medio impreso.

Burke, Peter. Visto y no visto. El uso de la imagen como documento histórico. Barcelona: Crítica, 2005. Medio impreso.

Camón Aznar, José. Summa Artis. Historia general del arte: la pintura española del siglo XVII, Vol. XXV. Madrid: Espasa Calpe, 1977. Medio impreso.

Culla y Clarà, Joan. "Ni tan jóvenes, ni tan bárbaros. Las juventudes en el republicanismo lerrouxista barcelonés". Ayer 59 (2005). 51-67. <http://ahistcon.org>. Sitio web.

Eco, Humberto. Historia de la fealdad. Barcelona: Lumen, 2007. Medio impreso.

Karush, Matthew. "Radicalismo y conflicto obrero urbano. 1912-1930". Nueva historia de Santa Fe. El Siglo Veinte. Problemas sociales, política de Estado y economías regionales: 1912-1976, Tomo IX. Dir. Oscar Videla. Rosario: Prohistoria / La Capital, 2006. 39-84. Medio impreso.

Gombrich, Ernst. Historia del arte. Barcelona: Garriga, 1995. Medio impreso.

Huyssen, Andreas. Modernismo después de la posmodernidad. Buenos Aires: Gedisa, 2010. Medio impreso.

Malosetti Costa, Laura. “Tradición, familia, desocupación”. Los estudios de arte desde América Latina: temas y problemas. Dir. Rita Eder. México: UNAM, 2003. <http: servidor.esteticas.unam.mx>. Sitio web.

---. "Los "gallegos", el arte y el poder de la risa. El papel de los inmigrantes españoles en la historia de la caricatura política en Buenos Aires (1880-1910)”. La memoria compartida. España y la Argentina en la construcción de un imaginario cultural (1898-1950). Comp. Yayo Aznar y Diana Wechsler. Buenos Aires: Paidós, 2005. 245-270. Medio impreso.

---. "Ernesto de la Cárcova. Sin pan y sin trabajo". Museo Nacional de Bellas Artes. Colección, Vol. IV. Comp. Roberto Amigo. Buenos Aires: Arte Gráfico Editorial Argentino, 2010. 426-429. Medio impreso.

Marchán Fiz, Simón. "Las artes ante la cultura visual. Notas para una genealogía en la penumbra”. Estudios Visuales. La epistemología de la visualidad en la era de la globalización. Ed. José Luis Brea. Madrid: Akal, 2005. 75-90. Medio impreso. Mauro, Diego, Fernando Cesaretti y Hernán Uliana. "Del resplandor a la opacidad. Opinión pública, empresas periodísticas y ciudadanía. La "nueva prensa” de Rosario en la década del 20: los casos de La Reacción y Reflejos". Imaginarios y prácticas de un orden burgués. Rosario, 1850-1930. Los actores entre las palabras y las cosas, Tomo I. Dir. Marta Bonaudo. Rosario: Prohistoria, 2005. 97-123. Medio impreso.

Mouguelar, Lorena. "Efigies o crucificados. Las caricaturas de Con Permiso". Actas del III Congresso Internacional do Nucleo de Estudos das Americas. Río de Janeiro: Universidad Estadual de Rio de Janeiro, 2012. Medio digital.

Neveleff, Julio y Graciela Di Iorio. La Argentina sin careta. José María Cao. Ilustraciones 1893-1918. Buenos Aires: Fundación Osde, 2007. Medio impreso. 
Persello, Ana Virginia. "Los gobiernos radicales: debate institucional y práctica política”. Nueva Historia Argentina. Democracia, conflicto social y renovación de ideas (1916-1930). Dir. Ricardo Falcón. Buenos Aires: Sudamericana, 2000. 59-99. Medio impreso.

Saítta, Sylvia. "El periodismo popular en los años veinte". Nueva historia argentina. Democracia, conflicto social y renovación de ideas (1916-1930). Dir. Ricardo Falcón. Buenos Aires: Sudamericana, 2000. 435-471. Medio impreso.

Söhle, Jorge. "El periodismo en Rosario. 1854-1910". Tercer Censo Municipal del Rosario de Santa Fe. Rosario: Talleres La República, 1910. 142-160. Medio impreso.

Szir, Sandra. Infancia y cultura visual. Los periódicos ilustrados para niños (1880-1910). Buenos Aires: Miño y Dávila, 2007. Medio impreso.

---. "Entre el arte y la cultura masiva. Las ilustraciones de ficción literaria en Caras y Caretas (1898-1908)". Impresiones porteñas. Imagen y palabra en la historia cultural de Buenos Aires. Comp. Laura Malosetti Costa y Marcela Gené. Buenos Aires: Edhasa, 2009. 109-139. Medio impreso.

Walther, Ingo. Los maestros de la pintura occidental. Una historia del arte en 900 análisis de obras. Colonia: Taschen, 2002. Medio impreso.

Recibido: 30 octubre 2013

Aceptado: 28 marzo 2014 